\title{
O Uso das Novas TIC's Como Ferramentas de Apoio Pedagógico para o Ensino Fundamental II na Escola Érico Veríssimo
}

\author{
Nerivaldo Braz de Carvalho ${ }^{1}$; Gislene Farias de Oliveira ${ }^{2}$
}

\begin{abstract}
Resumo: O objetivo do presente estudo é uma análise do uso das novas tecnologias como ferramenta de apoio pedagógico na Escola Érico Veríssimo, município de Simões - PI. Mais especificamente, conhecer a utilização desses novos instrumentos tecnológicos, no Ensino Fundamental II da escola pesquisada. Trata-se de uma pesquisa de campo, exploratória e qualitativa, através de entrevista com os professores. Tomou-se como base referencial os autores: Oliveira (2010), Ponte (2000) e Moran (2000), dentre outros. Durante a pesquisa pode-se verificar as expectativas e opiniões dos sujeitos pesquisados a respeito de como estes dinamizam suas aulas com o apoio das TIC's diante das exigências da sociedade atual. Os educadores acreditam que as STIC's são ferramentas utilizadas na prática educacional e funcionam como elemento facilitador no processo ensino-aprendizagem, pois ajudam a construir situações que motivam os alunos, pois já fazem parte de uma realidade social.
\end{abstract}

Palavras - Chave: Ensino. Tecnologias; Aprendizagem. Inovação. Prática Pedagógica.

\section{The use of the Current ICT ss an Educational Tool Support for Teaching at Elementary School II Érico Veríssimo}

\begin{abstract}
The aim of this study is an analysis of the use of new technologies as teaching support tool at the School Erico Verissimo of Simões Municipality - PI. Specifically, know the use of these new technological tools in the school studied Elementary Education II. This is a field survey, exploratory and qualitative research through interviews with teachers. It was taken as referential basis the authors: Oliveira (2010), Bridge (2000) and Moran (2000), among others. During the search it can be seen the expectations and opinions of the individuals surveyed as to how they streamline their classes with the support of ICT to the demands of today's society. Educators believe that ICT tools are used in educational practice and act as a facilitator in the learning process as they help build situations that motivate students, as already part of a social reality.
\end{abstract}

Keywords: Education; Technologies; Learning; Innovation; Teaching practice

\section{Introdução}

Em uma sociedade moderna, onde todos os setores utilizam a tecnologia como auxílio para suas atividades, a escola pública ainda não está preparando seus alunos para usar essas ferramentas como ajuda no processo de aprendizagem.

\footnotetext{
${ }^{1}$ Graduado em Matemática e Normal Superior - Universidade Estadual do Piauí - UESPI. Especialista em Psicopedagogia - SOET. Mestrando em Educação pela Anne Sullivan University. Professor Efetivo da Rede Municipal de Ensino Simões - PI. Brasil. Email:nerybraz@hotmail.com;

${ }^{2}$ Psicóloga com Doutorado em Psicologia Social pela UFPB e Pós Doutorado em Ciências da Saúde. Docente na Universidade Federal do Cariri, Barbalha, Brasil. E-mail: gislenefarias@gmail.com.
} 
Id on Line Revista Multidisciplinar e de Psicologia

Id on Line Multidisciplinary and Psycology Journal

A Tecnologia da Informação e Comunicação pode e deve ampliar a visão de mundo do aluno, mas embora o governo disponibilize alguns equipamentos e programas para a rede de ensino, o que ainda é observado atualmente é um sistema que não atende completamente a realidade das escolas.

A sociedade atual vem passando por muitas mudanças em quase todas as áreas de conhecimento. Essas mudanças trouxeram como consequência a criação e inovação de meios de comunicação onde às mesmas acabaram atingindo e mudando o cotidiano das pessoas. A intensidade com a qual as tecnologias vêm impulsionando na sociedade acaba obrigando as pessoas se adaptarem para não se desatualizarem. E na educação ela está tomando espaço como auxilio de aprendizagem e conhecimento que venha a somar e proporcionar ao educador mais métodos para se trabalhar em sala de aula.

As tecnologias de informação e comunicação possibilitam um mundo de conhecimentos e informações e estas ferramentas sendo utilizadas no campo educacional possibilitará uma aprendizagem dinâmica e atrativa para os educandos.

O uso das Tecnologias de Informação e Comunicação- TIC's tornou-se fundamental nas últimas décadas e vem crescendo a cada dia devido à troca intensiva de informação e comunicação entre as pessoas. A globalização tem provocado diversas mudanças com relação ao desenvolvimento social e com o uso das tecnologias atuais, a rotina escolar tem se transformado bastante, pois ela vem ajudando no desenvolvimento educacional, contribuindo para a melhoria da qualidade de ensino. Pensando nisso, resolveu-se pesquisar o uso das TIC's, a fim de observar se ela, de fato, teria uma contribuição significativa no processo de ensinoaprendizagem na escola Érico Veríssimo do município de Simões- PI.

O objeto de análise deste trabalho foi o uso das tecnologias atuais como ferramenta de apoio pedagógico para o ensino-aprendizagem dos alunos no Ensino Fundamental II da Escola Érico Veríssimo município de Simões-PI, com a finalidade de perceber quais professores já usam essas tecnologias como práticas inovadoras e se já percebem a contribuição dessas ferramentas para a melhoria do ensino.

Esse trabalho se constitui em uma pesquisa com abordagem quanti-qualitativa, com estudo de conceitos baseados em material já elaborado, e como ponto de partida o estudo foi fundamentado nas ideias de diferentes estudiosos da área que idealizam as tecnologias atuais 
Id on Line Revista Multidisciplinar e de Psicologia

Id on Line Multidisciplinary and Psycology Journal

como sendo algo indispensável para a melhoria no ensino, dentre outros estudiosos temos esses, Ferreira (2010) Mercado (2002) e Silva (2013), dentre outros.

A escolha dessa temática justifica-se por verificar a importância do uso das tecnologias no processo educacional, visto que a mesma vem acrescentando pontos positivos e inúmeros benefícios na educação, quando utilizado de forma correta, uma vez que professores e alunos têm uma intensa troca de conhecimentos.

De acordo com esses fatores citados acima e outras análises feitas na Escola Érico Veríssimo, este trabalho fará um diagnóstico que possa servir de subsídio para que os educadores possam buscar formas para utilizar as TIC como apoio nas suas atividades pedagógicas.

\section{As TIC's como Recurso Inovador na Prática Pedagógica}

No mundo virtual, cuja comunicação e as informações se processam de forma rápida, as pessoas tem se valido de recursos tecnológicos para manterem-se conectadas com o mundo em busca de inovações e melhorias para suas vidas, e, no campo educacional não tem sido diferente.

$\mathrm{Na}$ tentativa de mediar o ensino aprendizagem dentro desse novo contexto, os agentes envolvidos nesse processo têm tentado dar uma nova roupagem à sua metodologia com o propósito de ajudar no desenvolvimento do pensamento crítico, social e humano dos sujeitos, a fim de integrá-los na sociedade atual.

A esse respeito, Oliveira (2010), diz que o verdadeiro objetivo da informática na educação é promover um ensino inovador que possibilite o encontro e o intercâmbio entre todos envolvidos no processo de aprendizagem.

Nessa perspectiva, várias discussões vêm sendo levantadas, motivando a realização dessa pesquisa, com a finalidade de investigar as expectativas e opiniões dos professores do ensino Fundamental II da Escola Érico Veríssimo, na cidade de Simões-PI, e desenvolver, com auxílio das Tecnologias de Informação e Comunicação - TIC's, uma prática pedagógica condizente com os anseios da nova geração diante das demandas da sociedade atual. 
Na era da globalização marcada pela inovação tecnológica, já não há mais fronteiras para a intercomunicação. As mídias e tecnologias estão por toda parte, por isso, torna-se difícil desprender delas, de forma que, o grande desafio é adequar o modelo tradicional de educação ao uso de tecnologias e mídias pedagogicamente.

De acordo com Moran (2000)

Não se trata de dar receitas porque as situações são muito diversificadas. É importante que cada docente encontre o que lhe ajuda mais a sentir-se bem, a comunicar-se bem, ensinar bem, ajudar os alunos a que aprendam melhor. É importante diversificar as formas de dar aula, de realizar atividades, de avaliar.

Nesse contexto, é importante que o professor lance mão das mídias e das tecnologias atuais a fim de agregá-las às estratégias de ensino, como forma de mediar o conhecimento e promover a autonomia dos alunos, pois impactam as sociedades e impõe uma necessidade de reformulação nos modelos pedagógicos da escola.

Com base em estudo sobre as competências que devem ser trabalhadas no ensino fundamental II e observação na escola Érico Veríssimo para levantamento de informações, este trabalho mostra os recursos tecnológicos disponíveis para professores e alunos desempenharem suas atividades em sala de aula.

Diante do exposto, nos indagamos: Como são utilizadas as novas Tecnologias Educacionais no Ensino Fundamental II, na Escola Érico Veríssimo em Simões no Piauí?

\section{Metodologia}

Os procedimentos metodológicos utilizado na realização do presente estudo foram de abordagem quanti-qualitativa, visando analisar as ideias dos autores com relação ao tema proposto, discutindo a opinião dos professores entrevistados sobre o tema.

A pesquisa aconteceu na escola municipal Érico Veríssimo Simões PI. Os sujeitos pesquisados foram professores, diretores, coordenadores e alunos. A Escola pesquisada funciona em dois turnos, manhã e tarde, do infantil ao fundamental II, composta por 638 alunos e 48 funcionários, sendo 39 professores, 03 auxiliares de sala, 03 coordenadores, 01 diretor, 01 secretaria, 01 auxiliar de secretaria. 
Id on Line Revista Multidisciplinar e de Psicologia

Id on Line Multidisciplinary and Psycology Journal

Houve a necessidade de visitar a escola com o intuito de observar e descobrir se os profissionais de educação que atuam na referida escola estão preparados para utilizar as tecnologias como ferramenta de apoio pedagógico. Para coleta de dados, foram aplicadas questões abertas e fechadas para 10 professores e 10 alunos com o intuito de compreender como cada parte entende e trata a relação entre escola e o uso das TIC. Conhecer melhor os anseios dos alunos, as expectativas dos professores e os recursos disponibilizados pela escola.

\section{Resultados e discussões}

Segundo alguns entrevistados, o uso das TIC's é necessário no ambiente escolar, uma vez que enriquece as atividades propostas e desenvolve o interesse e interatividade dos alunos. É possível comparar os resultados obtidos na observação, a fim de analisar a importância de inserir as Tecnologias da informação e comunicação na escola Érico Veríssimo, enumerando as dificuldades encontradas para executar as TICS como ferramenta de apoio pedagógico na aprendizagem dos alunos.

Em visita a escola para observação e levantamento de dados sobre uso das TIC como ferramenta pedagógica, foi constatado que os professores e alunos disponibilizam de poucos recursos para utilizarem na prática, levando em consideração o grande número de alunos e professores que precisam dessas tecnologias. A instituição conta com datashow, televisão, computador, impressora, aparelho de DVD, lousa digital, microsystem, microfone, tela de projeção e caixa de som, sendo que nem todas são utilizadas, como a lousa digital, por não ter nem um profissional na instituição que saiba utilizar a ferramenta e por não terem recebido instruções para a utilização deste meio em favor do trabalho educacional.

$\mathrm{Na}$ escola havia uma sala de informática, que foi pouco utilizada por professores e alunos e hoje está desativada. E o desuso do laboratório de informática foi causado por muitos fatores, dentre os eles foi destacado: A baixa potência da energia elétrica, falta de internet, máquinas ultrapassadas e falta de uma pessoa capacitada para dá suporte técnico e auxiliar os professores e alunos.

É notórios que as principais dificuldades enfrentada pelos professores para inserir as tecnologias em suas práticas pedagógicas é a falta de habilidades para manusear esses 
Id on Line Revista Multidisciplinar e de Psicologia

Id on Line Multidisciplinary and Psycology Journal

equipamentos, sem falar que nas escolar também tem poucos recursos que podem ser utilizados pelos docentes e discentes.

De acordo com os PCN - Parâmetros Curriculares Nacionais para o Ensino Médio, na área de Linguagens, Códigos e suas Tecnologias são considerados competências básicas: "entender os princípios das tecnologias da comunicação e da informação, associá-las aos conhecimentos científicos, às linguagens que lhes dão suporte e aos problemas que se propõem a solucionar" (BRASIL, 2000).

O gestor da escola justificou que faltam recursos financeiros e suporte governamental para que a escola insira as TIC como auxílio no processo de ensino/aprendizagem. Para os professores entrevistados, há uma carência de recursos tecnológicos e capacitações para uma melhor utilização da Tecnologia de Informação e Comunicação nas tarefas pedagógicas. E os alunos entrevistados relataram que usam os recursos tecnológicos, principalmente as redes sociais, mas sentem dificuldades na hora de selecionar conteúdos para estudar e fazer cadastros em sites educacionais.

Segundo Masseto (2000), o importante, neste processo dinâmico de aprender pesquisando, é que o professor use técnicas e recursos para a boa efetivação das Tecnologias de Informação e de Comunicação, ou seja, que integre as dinâmicas tradicionais com as inovadoras, que unam a escrita com o audiovisual, o texto com o hipertexto, o encontro presencial com o virtual.

\section{Aspectos que envolvem a utilização das TIC's como ferramenta de Apoio Pedagógico}

Os resultados a seguir foram obtidos a partir de um questionário aplicado a dez professores e dez alunos do Ensino Fundamental II da Escola Érico Veríssimo município de Simões-PI. O mesmo objetivou conhecer todos os aspectos que envolvam a utilização das Tic's como ferramenta de apoio pedagógico para melhor a aprendizagem dos alunos. Dessa forma, buscou-se fazer um diálogo entre a teoria e os resultados obtidos na pesquisa para melhor entendimento do funcionamento dessas ferramentas como apoio pedagógico na referida escola.

Um dos questionamentos feito aos professores foi saber se eles utilizam recursos tecnológicos em sala de aula e quais tipos. Percebeu-se que esses recursos são utilizados durante 
Id on Line Revista Multidisciplinar e de Psicologia

Id on Line Multidisciplinary and Psycology Journal

as aulas, porem varia conforme a metodologia de cada professor. Através desta pergunta, notase que as tecnologias possibilitam apoio significativo para a dinamização e criação de aulas atrativas aos alunos da escola campo de pesquisa.

De acordo com Ponte (2000) as Tic's podem ajudar na aprendizagem dos educando através da possibilidade de criar métodos criativos e inovadores de ensino aprendizagem e de permitir o surgimento de espaços de interação e comunicação.

Quando questionados sobre a contribuição dos recursos tecnológicos para a aprendizagem dos alunos, apresentaram opiniões positivas. Um deles acrescentou que o uso dessas ferramentas tecnológicas do mundo moderno, chama atenção dos alunos, tornando-os mais motivados facilitando assim, o trabalho dos professores, para que os mesmos possam transmitir conteúdos de forma prazerosa, abrindo caminhos para uma aprendizagem significativa, deixando os alunos mais compromissados com as atividades diárias nas escolas.

A outra questão feita aos professores refere-se às facilidades das atividades proporcionadas pelas tic's. Três deles disseram que facilita a compreensão, a participação, a qualidade no desenvolvimento da aprendizagem e ampliação do conhecimento dos alunos. Já outros quatros responderam que as tic's torna a aula atraente, dinâmica e acessível, despertando mais interesses em buscar novas informações que sirvam para acrescentar os conhecimentos dos alunos.

Outra questão abordada aos dez educadores foi saber o que precisava ser feito para tornar as tic's mais presentes em sala de aula. Notou-se que todos os professores compartilharam da mesma opinião, destacando a busca de novos conhecimentos tecnológicos, cursos de formação continuada e a revisão dos currículos escolares como alternativas para serem revistas pela comunidade escolar.

Conforme Moran (2000) cada educador pode encontrar meios de inserir a tecnologia e os seus recursos nas suas metodologias. Mas também é importante que o educador amplie e aprenda a dominar as tecnologias de informação e comunicação.

O uso dos recursos tecnológicos facilita o dialogo entre professor e aluno, as tecnologias envolvem o alunado facilitando a aprendizagem. É importante a inovação tecnológica para os alunos como também é papel do professor buscar novas metodologias que chamem atenção deles. Algo novo em sala facilita o feedback entre educando e educador e proporciona modernos meios de aprendizagem. 
Diante desta situação percebe-se que as TIC's tornam-se facilitadora no ensino aprendizagem por que possui uma infinidade de ferramentas que poderão ser usadas na pratica pedagógica. Para Mercado (2002) o uso das tic's auxilia os professores no seu papel de transmitir informações e conhecimentos de forma criativa e interativa entre os sujeitos em sala. E para os alunos contribui diretamente na construção de seu aprendizado.

Conforme afirma Mercado (1999) percebe-se que o professor é um elemento importantíssimo para a inserção e a interação das tecnologias na educação. Dessa forma, é necessária uma mudança de postura da escola e do professor perante as mudanças tecnológicas que ocorrerão no processo didático metodológico.

\section{Opiniões Dos Professores Da Escola, Quanto Ao Uso Das Tic's}

Levando em conta os itens pesquisados, os professores entrevistados afirmaram que a escola ainda não se enquadra nos padrões técnicos e pedagógicos que visem um trabalho voltado para o uso das TIC's no contexto escolar. E, que ainda falta muito para adequar aos avanços da atualidade.

Quatro dos dez professores (40\%) disseram que apesar de tentar inovar as aulas com ajuda das tecnologias atuais, não existe um projeto pedagógico nem equipamentos suficientes e adequados que ajudem a desenvolver um trabalho que atenda as expectativas da geração digital, considerando a dinamicidade desses alunos em meio às infinitas possibilidades de uso das TIC's dentro e fora da escola.

Acreditam ser possível uma ação conjunta entre os agentes envolvidos na educação, em prol da construção de um projeto político pedagógico que vise o uso das TIC's como ferramenta necessária para o desenvolvimento integral do aluno.

O depoimento de alguns professores pesquisados leva à compreensão de que apesar da escola não dispor de ferramentas necessárias, eles tem procurado utilizar as TIC'S das quais dispõem com o propósito de inovar as aulas. Porém, não tem sido suficiente para alcançar os anseios da clientela que, por sua vez, já são nativos digitais e nasceram na era de grandes avanços tecnológicos. 
Id on Line Revista Multidisciplinar e de Psicologia

Id on Line Multidisciplinary and Psycology Journal

Sobre essa questão, Silva (2013) diz que exigir que o professor inove sua prática pedagógica com o uso da tecnologia não terá muito efeito se a escola não estiver inserida nesse ambiente virtual, uma vez que o aluno já faz parte desse mundo. Dessa forma, a escola deve estar apta a oferecer uma educação que vise o uso consciente das tecnologias.

A escola não pode mais ficar alheia às mudanças do mundo atual, é preciso centrar-se na realidade dos alunos, tem que buscar estratégias que aproxime da realidade deles para que não fique só na transmissão de conteúdos, mas que possa refletir acerca da vinculação dessas ferramentas ao fazer pedagógico, de forma ajudar o educando a desenvolver o conhecimento e sentir-se apto a enfrentar o mundo no qual está inserido.

Para isso, é imprescindível que a escola esteja preparada tanto estrutural quanto humanamente, apropriando-se de recursos tecnológicos que ajudem a promover uma aprendizagem que vá ao encontro do desenvolvimento do potencial criativo do educando.

Conforme Moran (2002), é importante que a escola esteja atenta aos acontecimentos nos meios de comunicação, contextualizá-los em sala de aula a fim de dialogar com os alunos sobre a necessidade de filtrarem os conteúdos acessados e usá-los com responsabilidade, desenvolvendo seu senso crítico na perspectiva de uma educação emancipatória e consciente.

\section{O Uso das Tic's como Recurso Pedagógico complementar}

Ainda sobre o uso das TIC enquanto recurso pedagógico procurou saber como essas ferramentas auxiliam na construção do conhecimento do aluno. Dos 10 professores questionados, três deles tiveram respostas semelhantes no sentido de que em suas aulas, costumam utilizar data show para condensar os conteúdos em slides, bem como passar vídeoaulas, palestras e músicas, enfatizando que estas são de suma importância, vez que ajudam o aluno a investigar os fatos, acontecimentos e informações com mais profundidade, citando como exemplo a internet.

Dos professores pesquisados, quatro disseram utilizar apenas data show e notebook na explanação de conteúdos e vídeo e quando pede para os alunos pesquisarem, o faz como atividade extraclasse, vez que não se tem acesso à internet na escola, fator que segundo eles, 
Id on Line Revista Multidisciplinar e de Psicologia

Id on Line Multidisciplinary and Psycology Journal

inviabiliza o uso de muitos recursos úteis que leva o aluno a interagir com os colegas na busca de novos conhecimentos.

Num contexto geral, professores e alunos foram indagados se uso das TIC influenciava diretamente na construção de uma aprendizagem mais dinâmica e produtiva.

Interpretando as respostas dos professores, percebe-se que eles têm a mesma opinião, deixando evidente que uma aula com o uso das TIC tende a ser mais interessante, primeiro, porque envolve o público jovem, segundo porque possibilita aos professores exporem os conteúdos de maneira mais lúdica, mais atraente e por sua vez, mais envolvente, porém, acrescentam que só o uso das ferramentas não implica numa boa aprendizagem, é importante que o professor tenha domínio do conteúdo, saiba utilizar essas ferramentas, definindo objetivos que levem o aluno a tornar-se um ser crítico, participativo e agente construtor do conhecimento, a partir de políticas que visem à inclusão digital e social dos sujeitos/aluno.

Um dos professores que respondeu o questionário destacou uma escola bem equipada com recursos tecnológicos contribuiria muito para o sucesso do ensino aprendizagem, porém, ressalta que um modelo de ensino, onde teoria e prática estão distantes, é um fator que contribui muito para a desmotivação do aluno.

Sobre essa questão, Ferreira (2010), relata que o uso pedagógico das TIC funciona como elemento facilitador da aprendizagem, pois além de sua presença constante no cotidiano das pessoas, deixa as aulas mais atraentes, vez que trabalha a percepção dos sentidos.

Dos dez alunos que responderam às perguntas, oito deles responderam com a mesma linha de pensamento, disseram que apesar de não terem acesso à internet na escola, o uso dos recursos tecnológicos pelos professores para exposição de vídeos, de músicas e documentários torna as aulas mais interessantes e proveitosas, pois ajuda no desempenho de atividades e desenvolve a competência comunicativa.

Os outros dois disseram que apesar de interessante as aulas mediadas por essas ferramentas, preferem estudar pelo livro, uma vez que não podem comprar equipamentos como celular ou computador, além de residirem em locais em que não tem acesso à internet.

Conforme Moran; Masetto e Behrens (2000), apesar de crianças e jovens lidarem mais facilmente com as informações multimídias, tendo o livro como uma opção menos atraente, não se deve "limitar-se em uma ou outra forma de lidar com a informação, mas utilizar todas em diversos momentos". 
Id on Line Revista Multidisciplinar e de Psicologia

Id on Line Multidisciplinary and Psycology Journal

As opiniões expressas levam a crer que em meio a um mundo globalizado, o uso adequado das TIC possibilita um ensino-aprendizagem mais dinâmico e produtivo, podendo tornar-se um laboratório de construção e partilha do conhecimento. Entretanto, é necessário que o professor tenha um olhar crítico para perceber que esses instrumentos por si só não operam milagres e que "só terão seu real valor quando forem incorporados, conscientemente, às práticas pedagógicas da escola." (OLIVEIRA, 2010).

Os resultados apontam, também, que o fator sócio econômico tem influenciado para que a escola caminhe lentamente no que se refere a um planejamento que contemple o uso das TIC de forma satisfatória. A escassez de equipamentos e a falta de infraestrutura para operacionalizá-los dentro da escola, bem como a falta de condições financeiras por parte de alguns alunos que os impedem, por exemplo, de possuírem uma ferramenta moderna que sirva como apoio para a sua aprendizagem, e por residirem em uma região onde o acesso a internet é limitado, com isso dificulta significativamente o processo de desenvolvimento do ensino aprendizagem condizente com as demandas da sociedade contemporânea.

Nessa direção, os PCN enfatizam que características culturais e socioeconômicas podem justificar as diferenças significativas quanto à obtenção, uso e domínio dos recursos tecnológicos, considerando a precariedade e ou inexistência desses recursos em alguns lugares do País. (BRASIL. MEC. PCN, 1998)

Nessa perspectiva, os resultados demonstra que para o uso significativo das TIC com vistas à promoção de uma educação inclusiva, é preciso considerar os aspectos técnicopedagógico, econômico, cultural e sócio afetivo dos sujeitos envolvidos.

\section{Considerações Finais}

De acordo com o levantamento de dados realizado na escola e as informações adquiridas na análise documental, à escola Érico Veríssimo assim como a maioria das escolas públicas da região, está longe de alcançar os padrões mínimos para uso das TIC como recurso pedagógico em sala de aula. Lamentavelmente os professores e alunos ainda não estão assistidos pelos governantes com relação à inserção das TIC no ambiente escolar. Percebe-se que ainda falta muito a se fazer para acompanhar o grande avanço que as tecnologias vêm tendo nos dias atuais. 
Id on Line Revista Multidisciplinar e de Psicologia

Id on Line Multidisciplinary and Psycology Journal

A cada dia surgem novas ferramentas, novos aplicativos que podem ser explorados como suportes que trarão benéficos no processo de ensino-aprendizagem. Devido os professores não receber treinamentos e nem formação para manusear as ferramentas modernas e devido o pouco incentivo para usar as tecnologias atuais em sua pratica pedagógica, é preciso força de vontade por partes dos mesmos para trabalhar com esses novos recursos.

Verificou-se que, os docentes estão sendo desafiados pelos alunos e pelos avanços da modernidade para adequar seu fazer pedagógico às imposições feitas por eles e às transformações tecnológicas que o mercado consumidor gera.

Porem cabe refletir se usar as tecnologias substituindo a aula tradicional vai contribuir para a melhoria no processo ensino aprendizagem e se formará indivíduos autônomos e críticos. Aparentemente, parece fácil para o professor inserir uma nova ferramenta em sua docência, mas ainda existem muitas dificuldades para mudar a concepção e a prática de ensino para inserir as tecnologias na sua prática pedagógica, mas isso já é superação para alguns educadores da escola, pois, as tecnologias só vêm a somar positivamente no desenvolvimento da aprendizagem dos alunos.

Os resultados obtidos neste trabalho mostrou o significado do quão é válida a utilização das tic's nas escolas. As conclusões dos professores revelaram que o processo de ensino aprendizagem precisa sofrer mudanças positivas e que elas devem refletir diretamente nos alunos, possibilitando o seu crescimento.

Através da pesquisa realizada verificou-se que as Tecnologias de Informação e Comunicação (TIC's) é ferramenta de apoio na construção do aprendizado promovendo aos alunos mais interesse, dedicação, participação e motivação. Mais vale ressaltar que a necessidade de investimentos e formação continuada nesse aspecto é essencial para que os educadores continuem ou possam começar a lecionar usando estratégias criativas, modernas e produtivas.

É notório que o uso das TIC's na sala de aula é de grande importância, pois além de permitir ao professor inovar suas aulas com atividades mais dinâmicas, possibilita ao aluno uma interação maior com os demais colegas e professores, além de favorecer o conhecimento e a compreensão de outras culturas, aguçando o seu poder de criticidade e criatividade em meio a um mundo pleno de transformações. Através disso, constatou que mesmo abrindo um leque de possibilidades para o ensino das mais diversas disciplinas do ensino fundamental II da escola 
Id on Line Revista Multidisciplinar e de Psicologia

Id on Line Multidisciplinary and Psycology Journal

Érico Veríssimo, os recursos tecnológicos sozinhos não motivarão os alunos, daí a importâncias dessas ferramentas serem mediadas pelos professores para que sirvam de motivação, trazendo melhoria e maior qualidade do ensino contemplando assim, todos os alunos da escola supracitada.

Vale ressaltar que mesmo com os avanços, o cenário escolar ainda está aquém da realidade atual, pois vivendo em um mundo globalizado onde a tecnologia se modifica constantemente, os educadores têm dificuldades em acompanhar esse ritmo acelerado.

Pode-se fazer uma análise interpretativa de que mesmo tendo os recursos tecnológicos existentes na escola e professores para desenvolver uma metodologia em consonância com as TIC's, mas é preciso buscar meios que contemple as habilidades e criticidade do aluno e sua inserção na sociedade contemporânea, porque o modelo de educação vigente ainda encontra-se focado no ensino tradicional e não consegue impactar os anseios dos alunos em desenvolver sua autoaprendizagem.

Fazendo uma análise geral pode-se perceber que a maioria dos professores pesquisados, em meio aos desafios, almejam pela oferta de uma educação pautada no uso das novas TIC's como instrumento de auxílio à sua prática pedagógica em busca de uma educação inovadora e transformadora. Para que isso ocorra, subtende-se que é necessário que os agentes responsáveis pela educação, reflitam e exerça uma nova postura face à abertura e integração das TIC's no contexto escolar como mecanismo de transformação da educação em prol da formação plena do cidadão.

Diante da reflexão realizada nesta pesquisa, conclui-se que um profissional de educação atuante deve interagir cada vez mais com o meio, com a contemporaneidade e para tanto, novas experiências serão imprescindíveis e decisivas tornando suas aulas mais atrativa e prazerosa causando assim melhoria no processo de ensino e aprendizagem.

\section{Referências}

BRASIL. MEC. Secretaria de Educação Fundamental. Parâmetros curriculares nacionais: Terceiro e quarto ciclos do ensino fundamental: Introdução aos Parâmetros Curriculares Nacionais. Brasília: MEC/SEF, 1998. 137p.

BRASIL. Parâmetros Curriculares Nacionais (Ensino Médio). Parte I - Bases Legais, 2000. Disponível em: < http://portal.mec.gov.br/seb/arquivos/pdf/blegais.pdf > Acesso em: 28 de jun. 2016. 
Id on Line Revista Multidisciplinar e de Psicologia

Id on Line Multidisciplinary and Psycology Journal

FERREIRA, Edilene Lucena. O uso pedagógico das tecnologias da informação e comunicação no ensino e na aprendizagem da língua inglesa. 2010. 126 f. Dissertação (Mestrado em Educação) Centro de Educação Programa de Pós-Graduação em Educação, Universidade Federal da Paraíba, João Pessoa 2010. 105p.

MASETTO, M. T.. "Ensino e aprendizagem inovadores com tecnologias audiovisuais e telemáticas:”. In: MORAN, J.M. MASETTO, M. T. e BEHRENS, M.A. Novas Tecnologias e Mediação Pedagógica. 12a ed. São Paulo, Papirus , 2000.

MERCADO, L. P. L.. Formação continuada de professores e novas tecnologias. Maceió. EDUFAL, 1999. 14p.

2002. 131p.

(Org.). Novas tecnologias na educação: Reflexões sobre a prática. Maceió. EDUFAL,

MORAN, José Manoel, MASETTO, Marcos e BEHRENS, Marilda. Novas Tecnologias de Mediação Pedagógica. São Paulo, Papirus Editora, 2000

Novas tecnologias e mediação pedagógica. 6. ed. Campinas: Papirus, 2000.

Desafios da televisão e do vídeo à escola. 2002. Disponível on-line em: http://www.eca.usp.br/prof/moran.

PONTE, J. P. da. Tecnologias de informação e comunicação na formação de professores: que desafios? Revista Ibero Americana, $n^{\circ}$ 24, setembro/dezembro, 2000. 14p.

OLIVEIRA, Déborah Ruchiga de; PACHECO, Samuel Bueno. Informática na educação 2. v.3 Rio de Janeiro: Fundação CECIERJ, 2010.71p.

SILVA, Luciene Amaral da. O uso pedagógico de mídias na escola: práticas inovadoras. Revista Eletrônica de Educação de Alagoas,v.1,n.1, 2013. Disponível em: http://www.educacao.al.gov.br/reduc/edicoes/1a-edicao/artigos/reduc-1aedicao/O\%20USO \%20PEDAGOGICO\%20DE\%20MIDIAS\%20NA\%20ESCOLA Luciene\%20 Silva.pdf Acesso em 25/10/2016.

Como citar este artigo (Formato ABNT):

CARVALHO, N.B.; OLIVEIRA, G.F. O Uso das Novas TIC's Como Ferramentas de Apoio Pedagógico para o Ensino Fundamental II na Escola Érico Veríssimo, Id on Line Revista Multidisciplinar e de Psicologia, Out-Nov. de 2016, vol.10, n.31, Supl 3, p. 217-230. ISSN: 1981-1179.

Recebido: 29/10/2016

Aceito: 31/10/2016 